Chirurgia (2018) 113: 19-37

No. 1, January - February

Copyright@ Celsius

http://dx.doi.org/10.21614/chirurgia.113.1.19

\title{
Recent Advances in Minimally Invasive Esophagectomy
}

\author{
Florin Achim, Silviu Constantinoiu
}

General and Esophageal Surgery Department, Center of Excellence in Esophageal Surgery, Sf. Maria Clinical Hospital, Bucharest

Corresponding author:

Florin Achim, MD

Center of Excellence in Esophageal

Surgery, Sf. Maria Clinical Hospital

Bucharest, Romania

E-mail: achim.llorin@yahoo.com

\section{Rezumat}

Progrese recente în esofagectomia minim invazivă

Tratamentul cancerului esofagian a devenit mai eficient datorită progreselor tehnicilor chirurgicale, abordării multidisciplinare, utilizării adecvate a terapiei neoadjuvante şi a îngrijirii perioperatorie în cadrul unor centre de excelență în chirurgia esofagiană. Esofagectomia este una dintre cele mai complicate şi exigente proceduri dintre toate interventiile chirurgicale gastro-intestinale cu o curbă foarte lungă de învățare în care excelența se poate atinge doar prin perfectionare de-a lungul întregii cariere chirurgicale. Rezultatele esofagectomiei sunt legate nu numai de volumul de cazuri operate ci şi de experiența chirurgilor în managementul complicațiilor postoperatorii. Inițial, esofagectomia minim invazivă a întâmpinat obstacole în implementarea sa în mai multe centre datorită costurilor şi complexității tratamentulului cancerului esofagian. Mai multe metaanalize şi studii clinice publicate până în prezent susțin fezabilitatea abordului minim invaziv, avantajele procedurii din perioada imediat postoperatorie precum şi echivalența rezultatelor oncologice cu tehnica clasică, ceea ce constituie un pas important în impunerea tehnicilor minim invazive ca standard în tratamentul cancerului esofagian. În această lucrare, ne propunem să urmărim progresele recente în esofagectomia minim invazivă, evoluția tehnicilor chirurgicale endoscopice prin prisma experienței personale şi a rezultatelor studiilor publicate în literatura de specialitate în ultimii ani.

Cuvinte cheie: cancer esofagian, esofagectomia minim invazivă, esofagectomia clasică, studiu clinic randomizat 


\section{Abstract}

The treatment of esophageal cancer has become more effective due to advances in surgical techniques, multidisciplinary approach, appropriate use of neoadjuvant therapy and perioperative care at centers of excellence in esophageal surgery. Esophagectomy is one of the most complicated and demanding procedures among all gastrointestinal surgeries with a very long learning curve in which excellence can only be achieved through improvement during all the surgical career. The results of esophagectomy are related not only to the volume of cases operated but also to the experience of surgeons in the management of postoperative complications. Initially, minimally invasive esophagectomy has encountered obstacles to implementation in several centers due to the cost and complexity of esophageal cancer treatment. Several meta-analyses and clinical trials published so far support the feasibility of the minimally invasive approach, the advantages of the post-operative period and the equivalence of oncological outcomes with the open technique, which is an important step in imposing minimally invasive techniques as a standard in the treatment of esophageal cancer. In this paper, we aim to analyze recent advances in minimally invasive esophagectomy, the evolution of endoscopic surgical techniques through our personal experience and the results of studies published in the medical literature in the last years.

Key words: esophageal cancer, minimally invasive esophagectomy, open esophagectomy, randomized controlled trial

\section{Introduction}

Esophageal cancer (EC) is the eighth most common type of neoplasm diagnosed worldwide. Also, EC is the sixth most common cause of death by neoplasms with a 5-year survival rate of $20 \%$ because approximately $50 \%$ of patients are diagnosed at an advanced stage. In Europe, it is only the $19^{\text {th }}$ most common type of cancer, but the mortality rates associated with esophageal adenocarcinoma (which account for only $10 \%$ of all cases of oesophageal neoplasia globally), have exceeded in some regions those of esophageal squamous cell carcinoma. Distribution by sex is equal to squamous cell carcinoma and adenocarcinoma is three times more common in males than in women. The main risk factors for squamous cell cancer in Western countries are smoking and alcohol consumption, while adenocarcinoma occurs predominantly in patients with gastroesophageal reflux disease or with an increased body mass index (1).

The treatment of esophageal cancer has become more effective through a multidisciplinary approach and the creation of centers of excellence with a large volume of esophageal pathology. Progress in staging, surgical technology, neoadjuvant therapy and perioperative care have reduced morbidity and mortality. The basic principle of curative treatment for the localized disease is surgery associated with neoadjuvant chemoradiotherapy for locally advanced stages.

Esophagectomy with locoregional lymphadenectomy is the standard treatment of patients with resected esophageal neoplasm and is associated with increased morbidity (40-50\%), mortality (8-11\%), low survival rate at 5 years of approximately $36 \%$ (even in experienced centers) and long postoperative recovery. Esophagectomy with esophageal reconstruction is a complex procedure requiring thoracic, abdominal or cervical approach and is recommended to be performed in centers with at least 20 cases operated per year (2). Postoperative and long-term outcomes are influenced by several factors: patient selection, versatility in surgical procedure selection, standardized perioperative clinical care protocols, prompt intervention in the treatment of postoperative complications and multidisciplinary co-operation. 
For invasive carcinoma, classical transthoracic esophagectomy (open esophagectomy$\mathrm{OE}$ ) is accepted as the best oncological operation because it allows complete tumor resection (R0), extended lymphadenectomy and restoration of digestive transit with intrathoracic or cervical anastomosis with a low rate of intraoperative complications. The pronounced systemic inflammatory response associated with significant trauma to thoracotomy and/or laparotomy determined the introduction of minimally invasive surgical techniques in the therapeutic arsenal.

Minimally invasive esophagectomy (MIE) has a relatively recent history, its introduction into practice is due in particular to the development of endoscopic surgery techniques. The first results reported in the medical literature appeared in 1992 when the first thoracoscopic esophagectomy was performed by Sir Alfred Cuschieri (3). In the search for an ideal technique for esophagectomy were performed in the minimally invasive manner all types of approach practiced in open surgery, including assisted robotic (4-6). MIE is a less traumatic procedure, allows for increased visualization of the operative field, simplification of postoperative care (blood transfusions, postoperative pain management), less incidence of postoperative complications, especially pulmonary infections, and postoperative DVT), shorter hospitalization and faster social reinsertion.

The minimally invasive approach requires mandatory experience in open esophageal surgery (which is difficult to obtain), advanced skills in endoscopic surgery, and the supervision of the first operations by an experienced mentor (7). The duration of surgery, the morbidity and mortality associated with the procedure and the long learning curve (at least 35 operations) may initially be important obstacles in implementing the minimally invasive approach (8).

Better recovery and faster social reinsertion may reduce the higher surgical costs of endoscopic surgical instruments, however, in order to reduce the duration of surgery, even in classic esophagectomy, mechanical devices are used to create faster the gastric conduit or to perform the intrathoracic anastomosis. Comparative studies in the literature did not report a difference in the real cost of MIE and had included postoperative complications, which are significantly associated factors of hospital costs also in open esophagectomy (9).

The main techniques that have been imposed in current practice are: the threestage esophagectomy through the modified McKeown thoracoscopic, laparoscopic and cervical approach ((performed in left lateral position (Luketich, 1998) or in prone position (Cuschieri, 1994)), two-stage esophagectomy by modified Ivor Lewis approach, laparoscopic and thoracoscopic (Watson, 1999), transhiatal esophagectomy by modified Orringer (DePaula, 1995) approach, laparoscopic and cervical and robotic-assisted esophagectomy (Horgan, 2003).

The MIE through the modified McKeown triple approach is the most commonly used worldwide since it provides a good visual field for mediastinal lymphadenectomy and by performing anastomosis at the cervical level avoids the complications associated with intrathoracic anastomotic leak (10). Image magnification and pneumoperitoneum used in the laparoscopic transhiatal approach help to accurately identify dissection plans with a lower risk of lesion of the pleura, direct esophageal branches of the aorta or other structures adjacent to the esophagus (thoracic duct), thus reducing the risk of bleeding or the appearance of the chylothorax. The increase in the incidence of esophageal and esophageal junction adenocarcinoma in the western countries led to a more frequent use of two-stage MIE (laparoscopic and right thoracoscopic) with two-field lymphadenectomy followed by intrathoracic anastomosis in the upper mediastinum.

The prone position was used during the thoracoscopic esophagectomy and a much better exposure of the intrathoracic anatomical structures was obtained without fully collapsing the right lung and it can reduce the postoperative respiratory complications (11). Compared to the standard left lateral position, a much better approach at the level of the right 
hemithorax is obtained, with less amplitude of movement of the mediastinum, the exposure is much better behind the right pulmonary hill with much easier visualization of the vascular elements, the lung is moved from the operative field of esophageal dissection even by its own weight, and the esophagus is not the most lower point of right hemythorax, and thus the blood resulting from the dissection is leaving the operative field (as opposed to the left lateral left decubitus in which the blood stagnates in the dissection area and its aspiration is required) (12).

The thoracoscopic esophagectomy performed in the semi-prone position combines the advantages of left lateral left decubitus (allowing for rapid conversion) and prone position (better visualization and extended mediastinal lymphadenectomy) (13).

Some limitations of MIE that include twodimensional view and the low degree of freedom of movement in the narrow field of the mediastinum have been eliminated by robotic surgery. The robotic platform has reduced the complexity of thoracoscopic and laparoscopic maneuvers using the endo-wrist robotic arm technology (7-degrees instrumental articulation). The enhanced 3D image at the highest resolution and the ability to perform fine movements allow performing of extensive mediastinal lymphadenectomy and a safe intrathoracic esophageal-gastric "hand-sewn" anastomosis. Reducing the learning curve (20 procedures) compared to the standard MIE also may increase the number of specialists who can acquire specific skills in a short period of time (14).

\section{Preoperative Clinical and Paraclinical Evaluation}

Preoperative clinical and paraclinical evaluation includes, in addition to the clinical and endoscopic examination, a computerized tomography (thoracic and abdominal) for the local evaluation of the tumor process and the exclusion of the presence of hepatic or pulmonary metastases. Positron emission tomography (CT-PET) can prevent unnecessary surgery. However, peritumoral lymph nodes are often difficult to assess by PET due to the proximity of the primary tumor, and when the tumor is not completely stenotic, endoscopic ultrasound is useful in assessing the local lymph node extension.

Other additional investigations used are barium swallowing study that assesses esophageal tumor for palliation of dysphagia and hepatic ultrasound that is useful for detecting liver metastases. A bronchoscopy and an ENT exam are recommended for tumors located above the tracheal bifurcation or those in close contact with the left bronchus. In case of locally advanced esophageal distal adenocarcinoma (T3/T4) involving the esophagealgastric junction, a diagnostic laparoscopy is recommended to exclude peritoneal metastases, which may be present in approximately $15 \%$ of patients (15). Tumor staging according to the AJCC/UICC classification $\left(7^{\text {th }}\right.$ or $8^{\text {th }}$ edition) with the histological type, the degree of anatomopathological differentiation and the location of the tumoral process influence the prognosis of patients with esophageal cancer $(16,17)$. Medical evaluation, especially for patients who are scheduled for multimodal therapy and/or surgery should also include blood counts, liver, respiratory, cardiac and renal function tests.

Long-term survival rates have improved by detecting esophageal cancer at a less advanced stage, adequate treatment during the perioperative period and using multimodal therapy. Neoadjuvant treatments including modern irradiation techniques with appropriate fractional doses reduced the side effects and associated postoperative mortality rates. In patients in early stages of disease (cT1-2N0), esophagectomy is recommended without a neoadjuvant treatment (18). In stage IIb-III, neoadjuvant or adjuvant therapy is indicated because it increases resectability rate and long survival, and for stage IV, surgery only complements palliative treatment (19). Neoadjuvant treatment modifies local anatomy, and difficulty may arise in thoracoscopic mediastinal dissection, therefore, detailed paraclinical reassessment is important after its completion, however minimal invasive 
esophagectomy performed after chemoradiation is considered safe (20).

Patients with advanced neoplasm neoadjuvant treatment require additional nutritional support delivered by oral administration, naso-enteral tube or using a feeding tube due to low oral intake, dysphagia or odynophagia. Malnutrition is associated with increased operative risk, affect the quality of life of the patient, and is associated with low survival (21). The use of a feeding tube is not recommended in all patients with esophageal cancer undergoing multimodal therapy and should avoid compromising future reconstruction options and all variants should be considered (stent vs gastrostomy vs. jejuno-stomy, open vs. endoscopic vs. laparoscopic). Endoscopic and laparoscopic approach benefit from a faster surgical recovery but are not free from complications (dislocations, obstructions of jejunostomies or small bowel obstruction) that may require surgical intervention in a patient who is undergoing neoadjuvant treatment. In endoscopic approaches, the risk of esophageal dilatation and perforation or metastasis at the insertion site of the feeding tube cannot be ignored (22). From the clinical experience in the use of endoscopic percutaneous gastrostomy (PEG), we have not encountered further difficulties in preparing the gastric conduit.

\section{Indications and Contraindications}

MIE is indicated for the treatment of benign conditions requiring esophageal resection, such as post-caustic stenosis, scleroderma, dysmotilities or esophageal leiomyoma, as well as for patients with Barrett's esophagus (highgrade dysplasia) where endoscopic treatment has failed and there is a high risk of progression to adenocarcinoma. At the introduction of MIE in the treatment of oesophageal cancer, indications for the minimally invasive approach were early stages or tumors with a good response after neoadjuvant treatment. Nowadays, MIE indications for treatment of esophageal cancer are similar to those in open surgery and depend on tumor location, staging, the clinical status of the patient and comorbidities or preference of the surgical team. In patients with a history of thoracic surgery, thoracoscopic esophagectomy is contraindicated because, in the case of modified anatomy or adhesion, dissection would prolong the duration of the intervention and increase the risk of lung injury. Also, bulky tumors and locally advanced infiltrating tumors (T4), especially those in contact with the airway, are a relative contraindication to the thoracoscopic approach. Relative contraindications of laparoscopy include previous surgery on the upper abdomen.

\section{Pre-operative Assessment}

Pre-operative blood count, coagulation, renal and hepatic function are assessed and electrocardiogram, cardiac ultrasound, chest x-ray and pulmonary function tests are performed. Preoperative preparation of the patients involves low molecular weight heparin (LMWH), respiratory exercises and mechanical bowel preparation for eventual reconstruction with colon in case of an inappropriate gastric conduit.

\section{Operative Technique}

Endoscopic surgical developments have supported MIE and have resulted in better clinical outcomes through safe intraoperative hemostasis, shortening operative times and performing quality anastomoses. The $3 \mathrm{D}$ highdefinition three-dimensional thoracoscopic image (using the 3D HD standard, 3D video scope Endoeye Flex with 100 degrees of articulation or 3D robotic) and 4K Ultra HD improves depth perception and allows for more accurate lymphadenectomy and faster anastomosis compared to $2 \mathrm{D}(23,24)$. The single-port technique used in some centers does not compromise the extent of surgical resection or postoperative outcomes (25).

At the Center of Excellence in Esophageal Surgery at St. Mary's Hospital in Bucharest, we introduced the MIE through the modified McKeown triple approach to reduce the pulmonary complications rate. Based on the experience of the first cases, we have found that careful pre-operative selection of cases is important in order to have a higher probability 
of resectability without conversion to open surgery and to avoid accidents during thoracoscopy.

The surgical instruments used in the clinic for MIE usually contains the standard 3D HD laparoscopic surgery kit, trocars Thoracoport $11.5 \mathrm{~mm}$ for thoracoscopic approach, EndoGIA Universal Roticulator Stapler 3.0-2.0 mm with vascular cartridge white, gray or violet (Tri-Staple ${ }^{\mathrm{TM}}$ technology), Hem-o-lok ${ }^{\mathrm{TM}}$ system endoscopic vascular seal, Ligasure Endoscopic $5 \mathrm{~mm}$, Sonicision ${ }^{\mathrm{TM}}$ Ultrasonic $5 \mathrm{~mm}$, a linear stapler GIA $45-60 \mathrm{~mm}$ with blue or green cartridge, Penrose tube for esophagus isolation during thoracoscopy and an endoscopic retractor (EndoFan).

\section{Thoracoscopic Stage}

Antibiotic prophylaxis is used, an arterial line is inserted for monitoring the blood pressure and a central venous line is required. After the selective orotracheal intubation using the Carlens tube, for the thoracoscopic approach we used the left lateral position. The surgeon is located on the right side of the patient and the assistant and cameraman on the left side. Five work trocars are used as follows: a $10 \mathrm{~mm}$ optical trocar in the $8^{\text {th }}$ intercostal space anterior to the middle axillary line, three $10 \mathrm{~mm}$ working trocars (in the the $9^{\text {th }}$ intercostal space, behind the posterior axillary line, in the $7^{\text {th }}$ intercostal space, anterior of the anterior axillary line, in the $4^{\text {th }}$ intercostal space, on the anterior axillary line for the EndoFan) and a $5 \mathrm{~mm}$ working trocar anterior and inferior to the tip of the shoulder blade (Fig. 1).

After installing trocars, the lung is collapsing and the right hemothorax is explored. $\mathrm{CO} 2$ insufflation up to a pressure of $8 \mathrm{mmHg}$ can be used to collapse the lung. The first step is the incision of the pulmonary triangular ligament at the level of the inferior pulmonary vein that can be done with the Hook or Ligasure. This is followed by incision of the mediastinal pleura inferior and superior to the azygos vein. A $10 \mathrm{~mm}$ EndoFan is used to retract the lung. The azygos vein is dissected and carefully isolated and then cut after is stapled with an EndoGIA Ultra

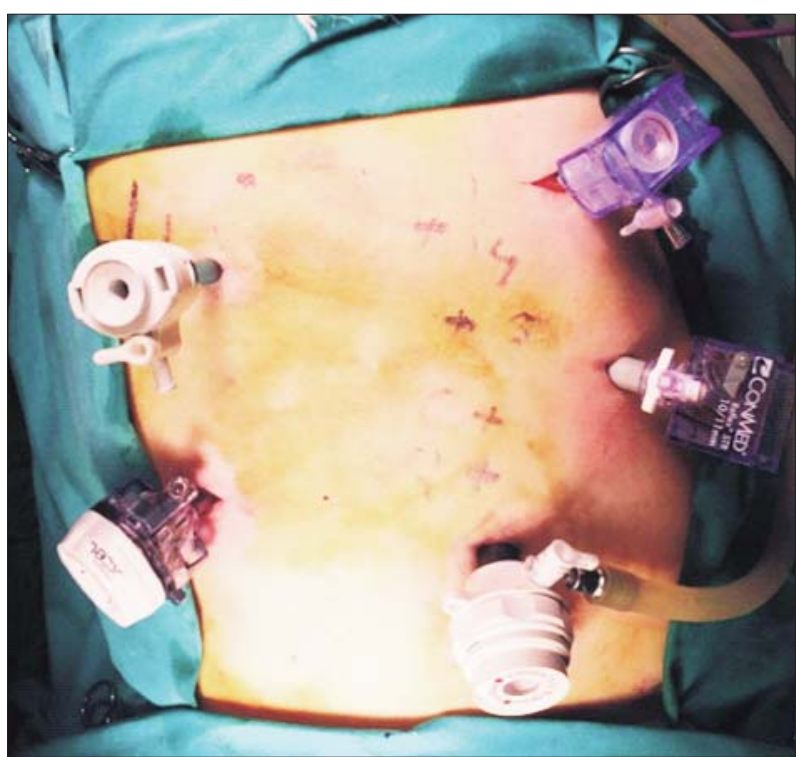

Figure 1. The position of trocars during thoracoscopy (collection of the Center of Excellence in Esophageal Surgery, Sf. Maria Clinical Hospital, Bucharest)

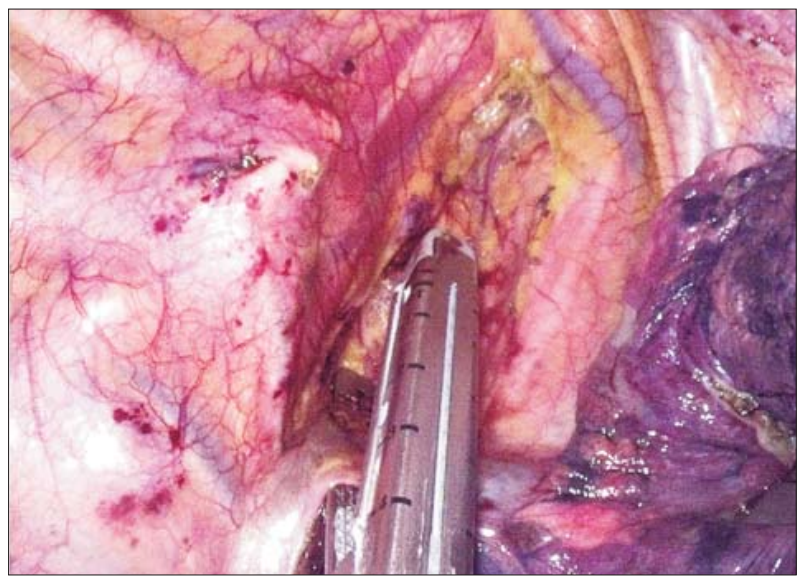

Figure 2. Section of the azygos vein (collection of the Center of Excellence in Esophageal Surgery, Sf. Maria Clinical Hospital, Bucharest)

vascular with a $3.5 \mathrm{~mm}$ or $45 \mathrm{~mm}$ white or gray cartridge depending on its size (Fig. 2). Continuing with the dissection of the thoracic esophagus and its isolation with a Penrose tube, at which time mediastinal lymphadenectomy is also practiced with the ultrasonic dissector or the Ligasure from the upper thoracic aperture to the distal esophagus (Fig. 3, Fig. 4). A safe hemostasis is performed using endoscopic clips for posterior aortic-esophageal vessels to prevent postoperative hemorrhage or chylo- 


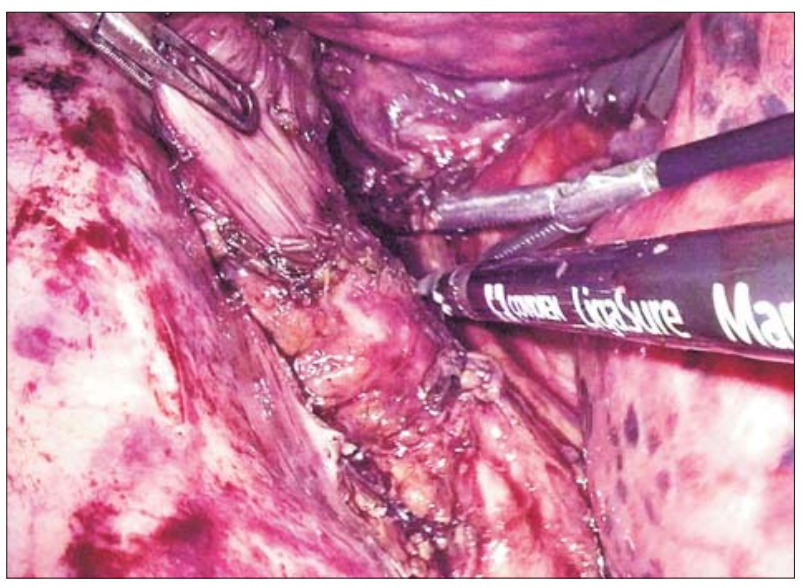

Figure 3. Dissection of the esophagus (collection of Center of Excellence in Esophageal Surgery, Sf. Maria Clinical Hospital, Bucharest)

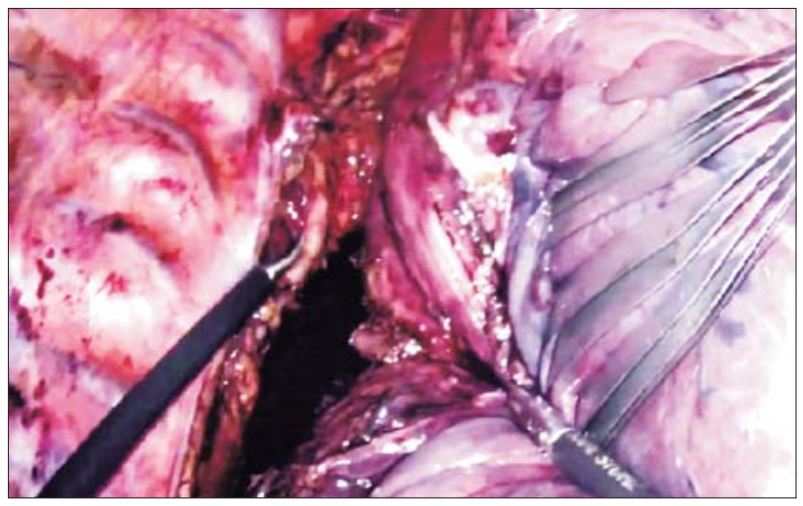

Figure 5. Identification of thoracic duct (collection of Center of Excellence in Esophageal Surgery, Sf. Maria Clinical Hospital, Bucharest)

thorax (Fig. 5). The dissection of subcarinal lymph nodes should be done with great care not to damage the main bronchi (Fig. 6). Pleural drainage is placed in the apex and at the base of the thorax adapted to a Béclaire closed drainage system, the lung is expanded under visual control, the trocars are extracted and the chest wounds are sutured.

For resection and extended lymphadenectomy, it was proposed to use virtual reality and sentinel ganglion detection that would allow exact localization of tumor and adjacent lymph node stations in real time, but to date, there is insufficient evidence to support the routine use of these techniques $(27,28)$. To prevent unilateral or bilateral recurrent nerve damage during

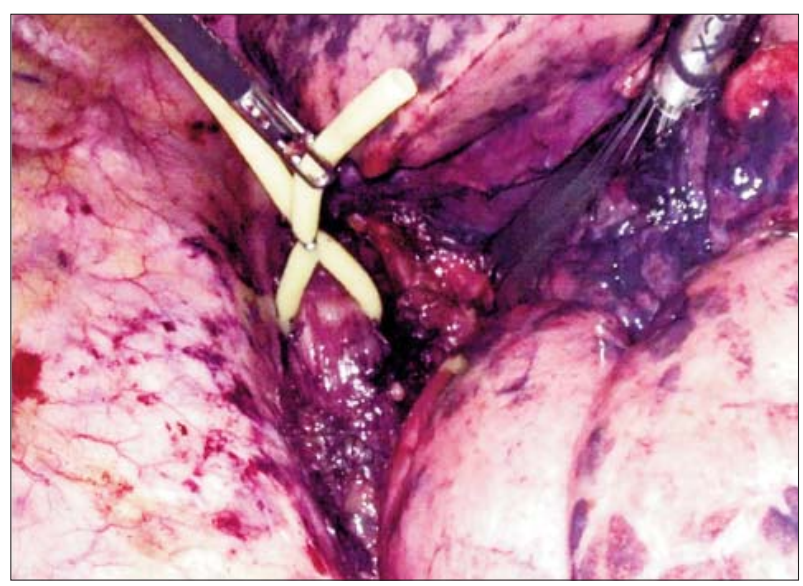

Figure 4. Isolation of esophagus (collection of Center of Excellence in Esophageal Surgery, Sf. Maria Clinical Hospital, Bucharest)

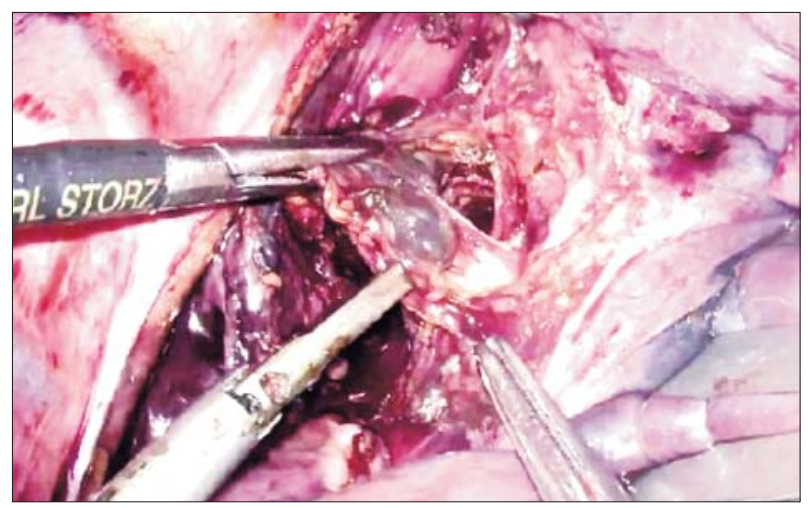

Figure 6. Mediastinal lymphadenectomy (collection of Center of Excellence in Esophageal Surgery, Sf. Maria Clinical Hospital, Bucharest)

extended lymphatic dissection (34-67\% incidence), continuous intraoperative monitoring was used (commonly used in thyroid surgery), but studies conducted to date did not report statistically significant differences in post-operative outcomes (29).

\section{Laparoscopic Stage}

Laparoscopic mobilization of the stomach is an important contribution to esophageal cancer surgery because it reduces the trauma of two-cavity operation to the patient and allows for the construction of a gastric graft comparable to that prepared by the open approach (30). The patient is placed in the French laparoscopic supine position, the 
Carlens selective orotracheal intubation tube is changed to one with a single lumen. Laparoscopic trocar position is described as follows: a $10 \mathrm{~mm}$ supraumbilical optical trocar on the umbilical line, three $10 \mathrm{~mm}$ work trocars (subxiphoid for EndoFan, supraumbilical lateral to the right medial-clavicle line, supraumbilical lateral to the left medialclavicle line) and a $5 \mathrm{~mm}$ trocar in the left upper quadrant used by instruments for traction and contraction (Fig. 7). After the creation of pneumoperitoneum, the optic trocar is introduced and the abdominal cavity is explored. The patient is placed in the Fowler position. The EndoFan is inserted into the subxiphoid trocar and helps to retract the left hepatic lobe from the work field and exposure of the esophageal-gastric junction. The vascular arch of the stomach is assessed. The gastrocolic ligament is divided in the middle and the dissection is continued to the left to the gastrosplenic and gastrophrenic ligament using the Ligasure or endoscopic clips (Fig. 8). To prevent possible detachment of clips during mediastinal pull-up is important to avoid using endoscopic clips on short gastric vessels.

The gastric conduit is prepared by following the preservation as the source of vascularization of the right gastroepiploic artery. Celiac lymphadenectomy is facilitated by upper traction of the stomach using the EndoFan. The hepatogastric ligament is sectioned, the omental pouch is opened and the adhesions of the posterior aspect of the stomach are dissected. The esophageal junction and the abdominal esophagus are dissected with the partial diaphragmatic crus sectioning to allow the conduit to ascend. Laparoscopic gastric mobilization is performed by cutting the left gastric pedicle with a vascular stapler and lymphadenectomy in the celiac plexus is completed (Fig. 9). The stomach is the preferred organ in esophageal reconstruction due to good vascular supply, it is long enough to avoid tension in anastomosis and is easy to prepare by the laparoscopic approach and for restoring digestive continuity is requiring a single anastomosis. However, if the stomach cannot be used, a colonic interposition can be performed.

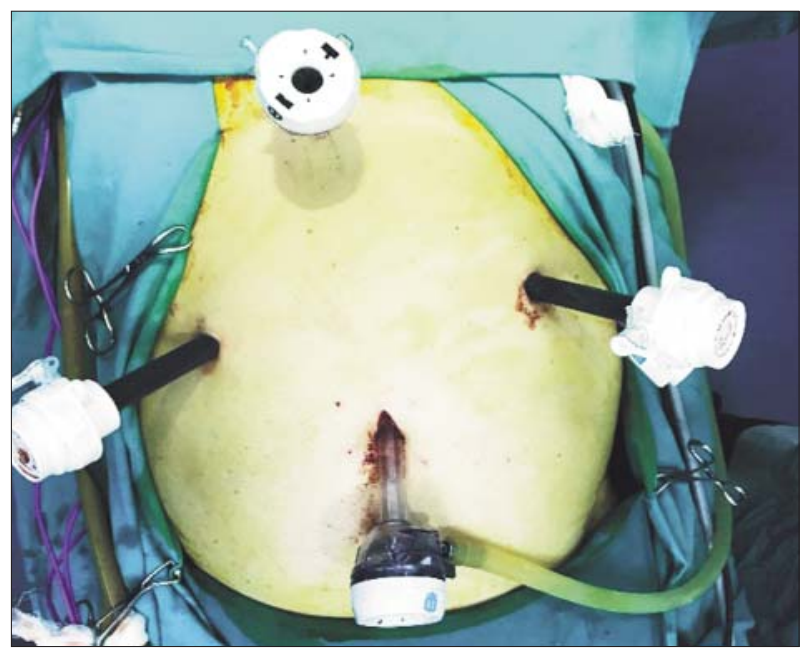

Figure 7. Position of trocar during laparoscopic stage (collection of Center of Excellence in Esophageal Surgery, Sf. Maria Clinical Hospital, Bucharest)

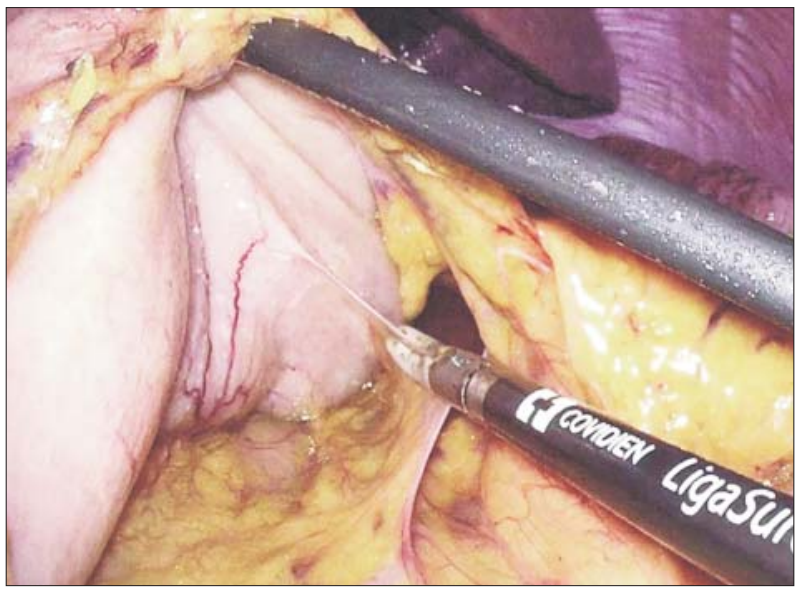

Figure 8. Laparoscopic preparation of the gastric conduit (collection of the Center of Excellence in Esophageal Surgery, St. Maria Clinical Hospital, Bucharest)

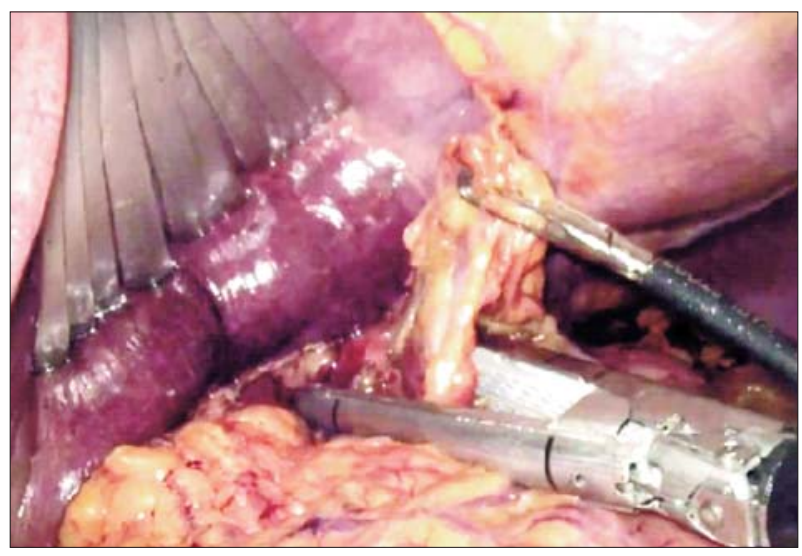

Figure 9. Division of the left gastric pedicle (collection of the Center of Excellence in Esophageal Surgery, St. Maria Clinical Hospital, Bucharest) 
Interposition of the right colon to restore gastrointestinal continuity was performed by Nguyen et al. with good results through the minimally invasive approach (31).

There are wide variations in the methodology used in the preparation of the gastric conduit. Some authors support the use of the entire stomach to keep collateral blood in the anastomosis in an effort to minimize the risk of complications of ischemia and anastomotic leak. Other authors support the use of a tubular stomach to optimize the length of the graft and its function after advancing in the chest or cervical. Luketich et al. reported an increase in the incidence of gastric necrosis and anastomotic fistula when using a narrower gastric tube $(3-4 \mathrm{~cm}$ in diameter); but by increasing the diameter of the gastric conduit to 5-6 cm, a decrease in anastomotic complications was observed (32).

Partial laparoscopic gastric devascularization performed before MIE has been proposed to improve stomach microcirculation by stimulating neovascularization. This is a safe technique and does not interfere with subsequent reconstruction, but it has not become a routine technique in esophagectomy. Schroder et al. performed a comparative retrospective study in 238 patients who had partial laparoscopic gastric ischemic devascularization by full stomach mobilization compared to 181 patients who had esophagectomy without devascularization but did not find any differences statistically significant in the incidence of anastomotic fistula (9.4\% vs. $7.6 \%)(33)$.

The objective evaluation of vascular changes during its preparation was also proposed to assist in choosing the optimal area for anastomosis and to eliminate the risk of ischemia. Traditionally, the evaluation of the viability of the gastric conduit is made by visual inspection of its color and by monitoring of the quality of bleeding the anastomosis site or the palpation of the arterial pedicle. Proper identification of vascular supply for the gastric conduit can be difficult during laparoscopic approach. Several methods of analysis blood perfusion of gastric conduit were used, including spectophotometry, CT angiography, Doppler ultrasound, intramuscular gastric $\mathrm{pH}$ measurement, but no significant reduction in anastomotic fistula was observed.

Recently introduced in the intraoperative real-time evaluation of gastric conduit perfusion, infrared angiography with indocyanine green (NIFA) is particularly useful during the learning curve to prevent intraoperative complications and avoid unintentional trauma. NIFA identifies gastric vascular supply with greater certainty and helps in the preparation of the gastric conduit, in choosing the optimal anastomosis site based on the vascular model and can be considered an important step in optimizing surgical technique and in reducing postoperative morbidity and mortality. Used by Zehetner et al. in 150 consecutive patients, a good infusion of the graft was found in $44 \%$ of the patients while the other patients had a demarcation line between the rapid infusion area and the slower perfusion of the fundus of the stomach. The rate of anastomotic fistula was significantly lower in patients where anastomosis was performed in the optimal perfusion area ( $2 \%$ vs. $45 \%, \mathrm{P}<0.0001)$ (34). The use of infrared imaging during minimally invasive esophagectomy may also be useful for detecting lymph node metastasis located in the proximity of the tumor and to guide lymphadenectomy extension or for evaluation of tumor margins (35).

\section{Left Cervical Approach}

A left cervical incision of 4 to $6 \mathrm{~cm}$ is practiced at the anterior margin of the sternocleidomastoid muscle. The dissection, isolation, and section the cervical esophagus is performed (Fig. 10). The distal extremity is closed and it is anchored to a Levine nasogastric tube, then esophagectomy specimen is extracted through a supraumbilical minilaparotomy. In the transition from open surgery to MIE, we have prepared the extracorporeal gastric conduit to prevent complications associated with this operative step.

Extracorporeal preparation of the conduit can be done using the Akiyama technique with creation of gastric conduit (at a width of 5-6 $\mathrm{cm}$ ) by resection of the small gastric curvature 


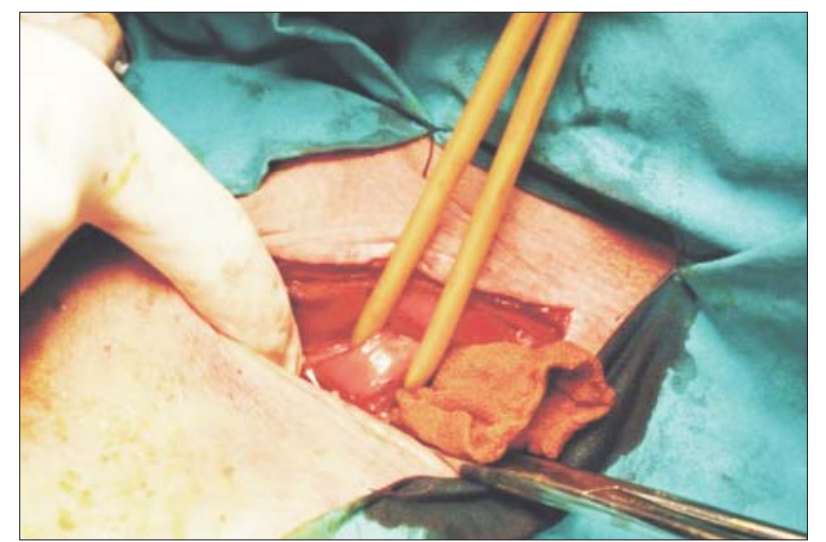

Figure 10. Left cervical approach with isolation of esophagus (collection of the Center of Excellence in Esophageal Surgery, St. Maria Clinical Hospital, Bucharest)

using a GIA linear stapler with green or blue cartridge and strengthening of the mechanical suture with Vicryl 3-0 or PDS 3-0 or using the Nakayama technique with section of the gastric conduit at the level of cardia (Fig. 11). MIE with the extracorporeal preparation of the gastric graft reduces the risks associated with the learning curve and has a positive impact on postoperative outcomes (36).

The association of delayed evacuation of the vagotomized gastric conduit after esophagectomy with the occurrence of anastomotic fistula determined the inclusion in the operative technique of extramucosal pyloromyotomy or Heinecke-Mikulicz pyloroplasty by laparoscopic approach. Pyloroplasty prolongs the duration of surgery and has its own risks and is not routinely indicated. Some studies have also found that there is no difference in the longterm functional outcome of delayed gastric evacuation (37). Many centers use chemical pyloroplasty by injecting intrapiloric botulinum toxin as prophylaxis against delayed gastric emptying, but the effects are temporary and the technique is not routinely used, and some authors find it is unnecessary in minimally invasive esophagectomy (38). Delayed gastric emptying after esophagectomy with gastric reconstruction can be treated with endoscopic pneumatic dilations with very good functional results (39). On the other hand, long-term survival of patients with esophageal neoplasm revealed the occurrence of major biliary reflux

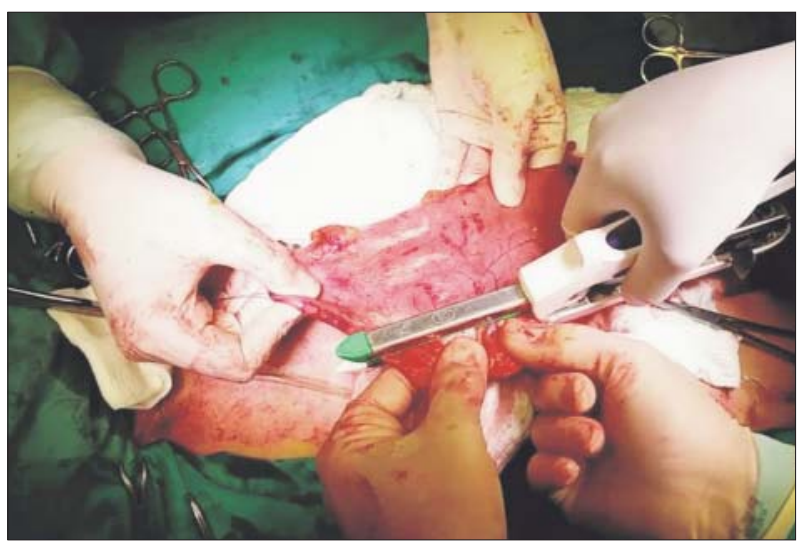

Figure 11. Extracorporeal preparation of the conduit (collection of the Center of Excellence in Esophageal Surgery, St. Maria Clinical Hospital, Bucharest)

and reflux oesophagitis, particularly in patients with MIE and intrathoracic anastomosis and pyloroplasty (40).

After preparation, the gastric conduit is attached to the Levine tube and is ascended cervical through the posterior mediastinum using the pull-up gastric technique and the end-to-side cervical esophageal-gastric anastomosis is performed with interrupted suture (3-0 PDS, 4-0 Silk) or continuous suture (4-0 Maxon). A 14Ch nasogastric tube is placed for postoperative drainage of the gastric conduit. A feeding jejunostomy is inserted for early enteral nutrition postoperatively. Feeding jejunostomies are routinely placed through the minimally invasive approach using Stamm, Witzel or Seldinger modified technique and are associated with low but not insignificant morbidity (41).

We prefer the triple approach to avoid intrathoracic anastomosis that may be complicated in the case of a mediastinal leak with the occurrence of mediastinitis and significant postoperative mortality. The experience accumulated over several decades in the hand-sewn or stapled manner of cervical anastomosis in open esophagectomy did not significantly reduce the fistula rate or anastomotic stenosis, despite it was performed end -to- $^{-}$ side or side-to-side (42). Stapled anastomosis reduces the duration of surgery and the incidence of postoperative anastomotic stenosis (43). In the case of anastomotic fistula, it can be 
treated conservatively by opening the cervical wound, and in the case of anastomotic stenosis, the endoscopic dilations can be performed. Also, cervical anastomosis has been associated with significant problems of swallowing and tracheobronchial aspiration which may increase the risk of pulmonary complications and can affect the general status of the patient (44).

Compared to cervical anastomosis, intrathoracic anastomosis can reduce anastomotic tension and reduce ischemia of gastric conduit and the incidence of anastomotic leaks or stenoses requiring endoscopic dilation. Also, the intrathoracic anastomosis was associated with better functional results with a lower incidence of dysphagia and recurrent nerve injury (45). Nowadays, several centers have stopped using the triple approach (including open or hybrid surgery) and they propose an intrathoracic anastomosis in the upper mediastinum by two-stage Ivory Lewis's laparoscopic and thoracoscopic approach to avoid cervical approach, while respecting oncological safety margins performing frozen sections histopathological examinations intraoperatively (46).

At the beginning of the use of the minimally invasive approach in the treatment of esophageal cancer, circular stapler devices were used to perform an end-to-side esophagealgastric anastomosis with the transoral insertion of the ORVIL (47). Subsequently, it was proposed to perform a wide side-to-side anastomosis $(6 \mathrm{~cm})$ to prevent stenosis $(48)$. The introduction of robotic surgery has proposed the "hand-sewn" intrathoracic anastomosis, using the V-Loc TM self-locking suture, yet it is considered technically demanding and therefore is not frequently used (49).

The laparoscopic preparation of an omental patch with blood supply from gastric large curve (a variant of the technique described by Goldsmith in 1968) was proposed to prevent an intrathoracic anastomotic leak. This is a useful technique because of its ability to induce neovascularization in the avascular areas, increasing the collateral blood supply (50). Currently, it is selectively used, most frequently in patients who have received neoadjuvant radiotherapy because it prolongs the surgery (51). Intraoperatively, the use of vasoconstrictors is avoided, a maximum of $2 \mathrm{~L}$ of intravenous solutions is administered, and a warm air blanket is used to maintain an intraoperative normal temperature. Drainage of the peritoneal cavity is routinely used.

\section{Intraoperative Incidents}

Among the most important incidents or accidents that may occur during thoracoscopy are the following: the introduction of the first trocar intraabdominal with possible liver damage, injury of large intrathoracic vessels, azygos vein, tracheal membrane, lung parenchyma or recurrent laryngeal nerve; they may in some cases cause conversion to open surgery. The average conversion rate reported in the literature is $5-7 \%$ depending on the used technique (52).

Also, during the dissection of the esophagus, pulmonary parenchyma can be traumatized and the injuries may take the form of a contusion (which can be treated conservatively) or even cause rupture of the pulmonary parenchyma that may require its suture or resection. Communication between surgical and anesthesia team is very important to prevent these incidents. The thoracoscopic mediastinal dissection may be technically difficult due to anatomical, clinical-pathological factors (tumor stage) or post-chemoradiation adhesions. Some studies have identified the mediastinal adiposity, the position of the spine in relation to the esophagus, or the size of the upper thoracic aperture as anatomic factors that may influence intraoperative blood loss or the duration of surgery $(53,54)$.

The injury of the thoracic duct is very rare and usually, is not recognized intraoperatively. During laparoscopy, the most common incidents are related to the mobilization of the stomach (injury of the gastro-epiploic right pedicle, the spline, the left liver lobe, or hemorrhage from the left gastric artery or short gastric vessels). These incidents are frequent during the learning curve of MIE and may affect the integrity of the gastric conduit in the immediate postoperative period. The 
meticulous attention during the laparoscopic preparation of the graft, the evaluation of venous drainage, the optimal dimensioning of the hiatus, the avoidance of tension in the gastric conduit, or the extracorporeal preparation are important factors in the prevention of its ischemia (55).

\section{Postoperative Period}

The duration of the operation is approximately 300 minutes, including the repositioning time of the patient. Patients are usually extubated in the operating theatre and transferred to the intensive care unit or high dependency unit. Early extubation may reduce the duration of admission to the intensive care unit (56). If the surgery was carried out without incidents and the patient had no cardiac-pulmonary comorbidities, it is extubated immediately after surgery. A chest X-ray is performed to assess the position of the drainage tubes after pulmonary expansion.

A standard postoperative clinical protocol for esophagectomy is used. High epidural anesthesia has clear benefits in relieving postoperative pain, facilitating faster extubation and early mobilization, thus reducing respiratory complications and duration of hospitalization. Respiratory physiotherapy is initiated and the feeding is started on the jejunostomy on the first day after surgery. Nasogastric drainage of the gastric conduit is maintained in the first postoperative days. Early mobilization of patients prevents lung complications, influences muscle strength, anxiety and quality of life of the patient (57). Hemo-dynamic monitoring and blood oximetry are very important after esophagectomy. Restriction of intravenous fluids according GDFT (gold directed fluid therapy) has positive effects on respiratory function. Administration of vasopressors should be avoided because they can reduce blood flow to the stomach conduit (58). Gastrointestinal, renal, neurological function are monitored and infectious risk is assessed by measuring the temperature, repeating the blood count, CRP and procalcitonin. Changes in post-operative consciousness in the absence of risk factors (age, associated pathology) may be the consequence of postoperative medical or surgical complications (59). The appearance of pleural drainage in the first days postoperatively may indicate the occurrence of the leak anastomotic, and the amount (approximately $100-400 \mathrm{ml} /$ day) expresses the functionality and also may show the presence of an air leakage. Radiological exam with iodine contrast agent is performed 5-7 days postoperatively, after which the oral feeding is gradually resumed and the Béclaire pleural drainage is suppressed.

Nowadays, there is no consensus on the optimal resumption of oral nutrition which is postoperatively replaced by enteral nutrition. Early postoperative oral nutrition recommended by nutrition guidelines may increase the incidence of lung or anastomotic fistulae due to the risk of tracheobronchial aspiration associated with esophagectomy (60). Starting an oral diet after esophageal surgery can improve postoperative recovery and quality of life, reducing discomfort in the use of the feeding jejunostomy. The patient is usually discharged in the second postoperative week if there are no septic or leak complications.

The follow up at 3 weeks postoperatively involves a clinical examination, assessment of nutritional status, pulmonary $\mathrm{x}$-ray, esophagealgastric barium swallow, upper gastrointestinal endoscopy and feeding jejunostomy is removed. The oncological follow up determines whether adjuvant chemotherapy is required depending on the final histopathological result, then the patients are re-evaluated at 6 months, 12 months, 24 months, 3 years and 5 years, or anytime if a postoperative complication occurs.

\section{Postoperative Complications}

Esophagus surgery involves extensive mediastinal dissection, a trauma of lung and peribronchus nerve structures and there is an increased risk of inoculation of a sterile area with bacteria from digestive cavities, conditions that may cause a generalized inflammatory syndrome (SIRS). The Clavien-Dindo classification is used to evaluate postoperative complications (61). Complications in the immediate postoperative period after esophagectomy (air leak, 
volvulus or gastric necrosis, thoracic duct injury, bilateral laryngeal recurrent nerve paralysis) may in some cases require emergency reoperation. Reintervention may be thoracoscopic/ thoracotomy, as appropriate, for graft excision, thoracic duct ligation at the hiatus, sealing of an air leak or other surgical procedures (cervical esophagostomy, tracheostomy).

Also, respiratory, cardiac and anastomosis leaks may influence the prognosis of patients requiring admission in the intensive care unit. Pulmonary complications are common after esophagectomy (30-60\%), approximately $80 \%$ are early complications and occur within the first five days postoperatively (atelectasis, bacterial pneumonia, and adult respiratory distress syndrome-ARDS). Using the minimally invasive approach has reduced the incidence of lung complications by reducing pulmonary parenchyma manipulation by using atraumatic instruments in the mediastinal dissection. Neoadjuvant treatments have not been associated with a significant increase in the risk of lung complications (62).

Intrathoracic anastomotic leak causes a strong systemic inflammatory response with severe mediastinitis, pleural empyema or sepsis difficult to treat. The incidence of intrathoracic anastomotic fistula reported in the literature ranges from $1 \%$ to $10 \%$ and was associated with a high postoperative mortality of approximately $60 \%$ if leak drainage is inadequate or if there is an important anastomotic defect. Reintervention for repositioning of drainage tubes or restoration of the anastomosis is associated with high mortality rates (20-32\%). Endoscopic interventions (endoscopic clips, bioadhesive injection or implantation of covered self-expandable stents, endoscopic vacuum therapy (E-VAC using an EndoSponge) are an alternative for treatment $(63,64)$. Approximation with endoscopic clips is difficult in case of a large anastomotic defect and the injection of fibrin adhesive is associated with a risk of thrombosis or embolization $(65,66)$. The endoscopic insertion of covered stents has a success rate of over $80 \%$, but is not without complications (stent migration, difficulty in removing the stent due to the growth of tissues and the development of anastomotic stenosis $(27.5 \%)$, which can be dilated endoscopically) $(67,68)$.

Cervical anastomotic leak benefits from conservative treatment with very good results. Drainage of the fistula through the cervical wound reduces the risk of sepsis, and the association of the enteral nutrition through the alimentary jejunostomy decreases the risk of postoperative mortality. The occurrence of anastomotic fistula is determined by certain specific risk factors for esophageal cancer and cervical anastomosis: malnutrition, neoadjuvant therapy, ischemia and atherosclerosis of the gastric conduit supply arteries, anastomosis technique, anastomosis tension, number of esophagectomy/year or the size of the upper thoracic aperture (69-72).

Long-term postoperative complications (delayed discharge of the gastric graft and hiatus hernia) are the result of the technical procedure. The use of prokinetic agents (Metoclopramide, Motilium, Erythromycin), pneumatic dilatation, or pyloric botulinum toxin injection are alternative treatments prior to a pyloroplasty (13). A hiatus hernia has an increased incidence after minimally invasive approach (7-9\%) compared to open esophagectomy possibly due to the reduction in postoperative adhesion formation and is becoming more relevant due to the increase in survival rate (74). The laparoscopic approach can be used to treat a hernia and the use of a mesh should avoid the risk of vascular injury of the gastric conduit (75).

Mediastinal dissection increases the risk of cardiac arrhythmias (3-18\%) that may cause hemodynamic instability and increased postesophagectomy morbidity, regardless of whether a minimally invasive or open approach is used (76).

\section{Discussions}

With a 25-year history of continuous development and refinement, the minimally invasive approach has been widespread throughout the world and is increasingly being used in the treatment of resected oesophageal cancer 
because it is a feasible alternative to the open approach and respects in at the same time the principles of oncological resection. Minimally invasive esophagectomy has not, however, been imposed as a standard treatment for esophageal neoplasm, and surgeons have not come to a consensus on the optimal technique for performing the minimally invasive approach. Different variants of the approach make it difficult to standardize minimally invasive esophagectomy techniques.

The three-stage McKeown modified approach, thoracoscopically, laparoscopically and cervically was initially preferred in several centers to avoid thoracic anastomosis, but the frequency of double laparoscopic and thoracoscopically modified Ivor Lewis approach has increased. An international study, conducted by Haverkamp et al., which assessed the trends in the last 10 years worldwide in surgical techniques used in the treatment of esophageal cancer and esophageal-gastric junction, has found an increase in the use of thoracoscopic esophagectomy from 14\% in 2007 to $43 \%$ in 2014. Cervical anastomosis is becoming less commonly used ( $54 \%$ vs. $87 \%$ in 2007) and is predominantly hand-sewn (64\%), while the thoracic anastomosis is performed mechanically (77\%) in most centers (77).

The first results of minimally invasive surgery for esophageal cancer found a much better control of postoperative pain, less recovery and fewer lung complications or infections of the wounds. These were followed by the criticism of those who performed minimally invasive esophagectomy, but with disappointing results (conversion rate of $10^{-}$ $17 \%$, pulmonary complications between $17 \%$ and $42 \%$ or mortality $3-12 \%$ ) that were not very different from those of open surgery (78).

A large number of meta-analyses or retrospective studies reported contradictory results of using of minimally invasive esophagectomy. Comparative studies between MIE and classical esophagectomy showed a similar duration of surgery, decreased intraoperative blood loss, a lower rate of lung complications, recurrent laryngeal nerve injury in fewer cases, a shorter duration of admission to the intensive care unit and the shorter period of hospitalization. Comparative studies supported the feasibility of the minimally invasive approach, with its advantages in the immediate postoperative period and similar results in terms of the mediastinal lymph node resection rate.

However, there are controversies about using the minimally invasive approach in practice because it requires a demanding and difficult technical support, is a laborious operative technique and has a long learning curve. The results of the minimally invasive approach are related to the activity of clinics that perform this surgery, the surgeons experience in minimally invasive thoracoscopic and laparoscopic surgery and the involvement of the intensive care team in the management of specific postoperative complications of this surgery. The equivalent results between the open and the minimally invasive approaches have not sufficiently motivated some centers to use the minimally invasive approach and were reluctant to change the standardized standard techniques used with good results for the treatment of esophageal cancer.

The first large series of minimally invasive esophagectomy with over 1,000 patients was published by Luketich et al. who reported results comparable to open technique in terms of oncology resectability (79). In the multicenter study conducted in collaboration with the Eastern Cooperative Oncology Group (2015), Luketich et al. found favorable immediate postoperative results of MIE with an incidence of ARDS of 5.7\%, pneumonia of $3.8 \%$, and of atrial fibrillation of $2.9 \%$, an average of 19 resected lymph nodes, negative margins (R0 resections) in $96 \%$ of patients, an average hospitalization duration of 2 days, a mean hospitalization of 9 days, an anastomotic leak rate of $8.6 \%$ and a mortality rate of $2 \%$. The 3 -year survival rate was $58.4 \%$ and was similar to that of the patients who received open esophagectomy and the loco- $^{-}$ regional recurrence was $6.7 \%$ (80).

In centers with experience in the minimally invasive approach to esophageal cancer who are currently using standardized surgical treatment protocols, the technical limits of 
minimally invasive esophagectomy has not been reached yet, as it still benefits from improvements, but we can state that postoperative results are in greatly influenced by the postoperative evolution specific to oesophageal pathology and resection and less by the operation itself and there are good arguments for using this approach.

The prone position, already used in many centers, for its ergonomic advantages and excellent operator field exposure, was associated with a shorter operator time compared to the left lateral decubitus (86 minutes vs. 123 minutes, Fabian et al.) and fewer lung complications $(6 \%)(81)$.

The robotic technique has also reduced MIE limits while preserving its advantages over open esophagectomy, the technically difficult steps of MIE with long learning curves such as pyloroplasty and thoracoscopic mechanical anastomosis are much easier performed. Mediastinal dissection, especially in patients with neoadjuvant therapy or those with locally advanced tumors, may be facilitated by superior optics and visualization provided by RAMIE. The simplification of operative performance and the potential reduction of chronic trauma and injury related to the use of endoscopic instruments, involving in particular long and complex operations, can be significant benefits for the surgical team (82). Fuente et al. (2013) reported postoperative results comparable to those of MIE standard or open technique (83). The cost of the equipment, the learning curve, the extended robot setting time and the instrument engineering limits are obstacles to use in more specialized centers. Van der Sluis et al. (2015) evaluated long-term oncology results of RAMIE with lymphadenectomy on two abdominal and thoracic fields and found that RAMIE is oncologically effective with a low percentage of local recurrence $(6 \%)$ and $42 \%$ overall 5-year survival) (84).

The first randomized multicenter study (TIME trial), which included 115 patients and compared thoracoscopic esophagectomy in prone position and laparoscopic preparation of the gastric conduit with standard postero- lateral thoracotomy and laparotomy (OE) followed by intrathoracic or cervical anastomosis reported the obvious short-term advantages of the MIE techniques in the first 2 weeks postoperatively ( $9 \% \mathrm{MIE}$ vs. $29 \%$ OE, $\mathrm{P}$ $=0.005$ ), less blood loss intraoperatively, a reduction in the incidence of postoperative pain, a shorter hospital stay (11 MIE vs 14 days $\mathrm{OE}, \mathrm{P}=0.044$ ), recurrent laryngeal nerve palsy in fewer patients ( $2 \%$ MIE vs $14 \%$ OE, $\mathrm{P}$ $=0.012$ ) and improvement of postoperative quality of life. The conversion rate to open esophagectomy recorded in this trial was $14 \%$. The rate of $\mathrm{R} 0$ resection, the number of dissected lymph nodes (20 MIE vs. $21 \mathrm{OE}$ ) and the rate of anastomotic fistula ( $7 \%$ OE vs. $12 \%$ MIE, $\mathrm{P}=0.390)$ and mortality $(1.8 \% \mathrm{OE}$ versus $3.4 \%$ MIE) were not significantly different (85). The study found a better quality of life in the first year after surgery and especially in the first 6 weeks postoperatively for patients who benefited from the minimally invasive approach compared to open esophagectomy (86). Patients experienced postoperatively a slow progressive improvement in physical activity that lasted 18-24 months until it reached a level comparable to preoperative level. Swallowing and nutrition problems required 18-24 months for readaptation, while dysphagia occurred in the immediate postoperative period, declining in intensity after 6-9 months and continued to improve at 18 months postoperative. A postoperative cough was present in the first 9 months, then with a reduction in intensity but without definitive disappearance at 24 months. Three-year outcomes (2017) showed no difference in survival without recurrence (37.3\% OE vs. $42.9 \%$ MIE) and overall survival (41.2\% OE vs. $42.9 \% \mathrm{MIE})$ for open or minimally invasive esophagectomy (87).

Another randomized, multicentre controlled trial (MIRO trial), which included 207 patients with esophageal oesophageal resection of the middle or distal third of the esophagus, evaluated hybrid minimally invasive esophagectomy HMIE (the modified Ivor Lewis approach laparoscopy and right thoracotomy) compared to open esophagectomy and was found that laparoscopic 
mobilization of the stomach significantly reduced postoperative morbidity (88). Major postoperative morbidity (grade II-IV, ClavienDindo) reported 30 days postoperatively, was much higher in patients who had an open approach (64.4\% OE vs. $35.9 \%$ HMIE). Pulmonary complications were less in patients with hybrid esophagectomy (17.7\% HMIE vs. $30.1 \%$ OE). Overall survival at 3 years (2017) was better in the HMIE group at $67.0 \%$ vs. $54.8 \%$ for the EC group $(p=0.05)$. These results demonstrate that HMIE is an oncologically safe procedure and significantly reduces postoperative morbidity (89). Based on these results, the authors recommend laparoscopic approach for gastric conduit preparation and hybrid esophagectomy as a standard treatment for patients with middle or distal resectable esophageal cancer.

The first randomized controlled trial designed to compare robotically assisted minimally invasive thoracolaparoscopic esophagectomy with open transthoracic esophagectomy as surgical treatment for resection of esophageal cancer (ROBOT trial) found equivalence between the two techniques in terms of short-term oncogene results. It also resulted in a lower percentage of postoperative complications, decrease in intraoperative blood loss and reduction of hospital admission and a better postoperative life quality compared to classical esophagectomy (90).

In a comparative analysis of postoperative quality of life after minimally invasive esophagectomy, Parameswaran et al. reported less asthenia at 3 months postoperatively and lower intensity of pain associated with gastrointestinal symptoms compared to open esophagectomy (91). In a retrospective evaluation of postoperative symptoms performed by Mehran et al. there was no difference in the functional results of the two approaches (92). Sundaram et al. have established that there are no significant differences in terms of quality of life parameters 12 months after surgery between MIE and open esophagectomy (93).

The continuing evolution of endoscopic techniques will support the improvement of MIE with much better postoperative outcomes than at present. Also, familiarizing young surgeons with minimally invasive techniques will further promote and enhance the use of MIE to become the first therapeutic option in any esophageal surgery center for early-stage cancer and tumors with good chemoradiation response.

We support the laparoscopic mobilization of the stomach to prepare the gastric conduit and also extracorporeal preparation for the surgeons who are in the learning curve. Also, assessing the vascularization with angiography with indocyanine green laser should become a routine. The intermediate position of the semi-prone position may be used for thoracoscopic esophagectomy to accommodate the different anatomical image in the transition from the lateral decubitus to the prone position. An anastomosis in the superior mediastinum that respects the oncology safety margins can avoid the complications of the cervical anastomosis. Pyloroplasty is not absolutely necessary and we do not recommend doing it routinely. The early resumption of enteral nutrition on the alimentation jejunostomy is used in many centers without significant complications (intolerance, hydro-electrolytic imbalance). The hybrid esophagectomy used with very good results compared to open esophagectomy is an important step in the implementation of minimally invasive techniques at the global level. Supported by the latest published results, we believe that it is time for minimally invasive esophagectomy to become the standard treatment recommendation for oesophageal cancer. Robotic-assisted esophagectomy will probably represent the future of resectable esophageal cancer.

\section{Conclusions}

Current treatment of esophageal cancer involves multidisciplinary cooperation. The surgical approach of the esophagus is difficult and reserved for centers specialized in esophageal pathology because it is associated with considerable morbidity and mortality and a long-term postoperative recovery.

Minimally invasive esophagectomy is a less 
traumatic surgical procedure with an easier postoperative recovery. MIE allows the simplification of postoperative care, the reduction of the incidence of postoperative complications, especially pulmonary, the decrease of the hospital stay and a faster social reintegration. Comparative studies published up to date in the literature have shown oncological results similar to classical esophagectomy.

However, the minimally invasive esophagectomy has a long learning curve, requires extensive experience in open esophageal surgery, but the robotic approach increasingly used to provide solutions to overcome this obstacle. Also, the technique is associated with high cost of surgical instruments, however, surgeons should choose an surgical approach based on clinical factors, rather than cost implications.

MIE is a safe technique that has already passed the test of time and, together with hybrid esophagectomy, should be the standard approach to the surgical treatment of esophageal cancer in centers of excellence in esophageal surgery.

\section{References}

1. Castro C, Bosetti C, Malvezzi M, Bertuccio P, Levi F, Negri E, et al. Patterns and trends in esophageal cancer mortality and incidence in Europe (1980-2011) and predictions to 2015. Ann Oncol. 2014; 25(1):283-90. doi: 10.1093/annonc/mdt486.

2. Fuchs HF, Harnsberger CR, Broderick RC, Chang DC, Sandler BJ, Jacobsen GR, et al. Mortality after esophagectomy is heavily impacted by center volume: a retrospective analysis of the Nationwide Inpatient Sample. Surg Endosc. 2017;31(6):2491-2497. doi: 10.1007/s00464-016-5251-9. Epub 2016 Sep 22.

3. Cuschieri A, Shimi S, Banting S. Endoscopic oesophagectomy through a right thoracoscopic approach. J R Coll Surg Edinb. 1992;37(1):7-11.

4. DePaula AL, Hashiba K, Ferreira EA, de Paula RA, Grecco E. Laparoscopic transhiatal esophagectomy with esophagogastroplasty. Surg Laparosc Endosc. 1995;5(1):1-5.

5. Watson DI, Davies N, Jamieson GG. Totally endoscopic Ivor Lewis esophagectomy. Surg Endosc. 1999;13(3):293-7.

6. Horgan S, Berger RA, Elli EF, Espat NJ. Robotic-assisted minimally invasive transhiatal esophagectomy. Am Surg. 2003;69(7):624-6.

7. Cuesta MA, van der Wielen N, Straatman J, van der Peet DL. Mastering minimally invasive esophagectomy requires a mentor; experience of a personal mentorship. Ann Med Surg (Lond). 2016; 13:38-41. doi: 10.1016/ j.amsu.2016.12.050. eCollection 2017 Jan.

8. Tapias LF, Morse CR. Minimally invasive Ivor Lewis esophagectomy: description of a learning curve. J Am Coll Surg. 2014;218(6):1130-40

9. Fu SJ, Ho VP, Ginsberg J, Perry Y, Delaney CP, Linden PA, et al. Complications, not minimally invasive surgical technique, are associated with increased cost after esophagectomy. Minim Invasive Surg. 2016;2016:7690632. doi: 10.1155/2016/7690632. Epub 2016 Dec 8.

10. Luketich JD, Nguyen NT, Weigel T, Ferson P, Keenan R, Schauer P. Minimally invasive approach to esophagectomy. JSLS. 1998;2(3):243-7.
11. Cuschieri A. Thoracoscopic subtotal oesophagectomy. Endosc Surg Allied Technol. 1994;2(1):21-5.

12. Javed A, Manipadam JM, Jain A, Kalayarasan R, Uppal R, Agarwal AK. Minimally invasive oesophagectomy in prone versus lateral decubitus position: A comparative study. J Minim Access Surg. 2016;12(1):10-5. doi: 10.4103/0972-9941.171954.

13. Kaburagi T, Takeuchi H, Kawakubo H, Omori T, Ozawa S, Kitagawa $Y$. Clinical utility of a novel hybrid position combining the left lateral decubitus and prone positions during thoracoscopic esophagectomy. World J Surg. 2014;38(2):410-8. doi: 10.1007/ s00268-013-2258-4.

14. Sarkaria IS, Rizk NP. Robotic-assisted minimally invasive esophagectomy: the Ivor Lewis approach. Thorac Surg Clin. 2014;24(2):211-22, vii. doi: 10.1016/j.thorsurg.2014.02.010.

15. Lordick F, Mariette C, Haustermans K, Obermannová R, Arnold D; ESMO Guidelines Committee. Oesophageal cancer: ESMO Clinical Practice Guidelines for diagnosis, treatment and follow-up. Ann Oncol. 2016;27(suppl 5):v50-v57.

16. Zahoor H, Luketich JD, Weksler B, Winger DG, Christie NA, Levy RM, et al. The revised AJCC Staging System (7th Edition) improves prognostic stratification after minimally invasive esophagectomy for esophagogastric adenocarcinoma. Am J Surg. 2015;210(4): 610-7. doi: 10.1016/j.amjsurg.2015.05.010. Epub 2015 Jun 26.

17. Rice TW, Patil DT, Blackstone EH. 8th edition AJCC/UICC staging of cancers of the esophagus and esophagogastric junction: application to clinical practice. Ann Cardiothorac Surg. 2017;6(2):119-130. doi: 10.21037/acs.2017.03.14.

18. Markar SR, Gronnier C, Pasquer A, Duhamel A, Beal H, Théreaux J, et al. Role of neoadjuvant treatment in clinical T2NOMO oesophageal cancer: results from a retrospective multi-center European study. Eur J Cancer. 2016;56:59-68. doi: 10.1016/j.ejca.2015.11.024. Epub 2016 Jan 23

19. Shapiro J, van Lanschot JJB, Hulshof MCCM, van Hagen $P$, van Berge Henegouwen MI, Wijnhoven BPL, et al. Neoadjuvant chemoradiotherapy plus surgery versus surgery alone for oesophageal or junctional cancer (CROSS): long-term results of a randomised controlled trial. Lancet Oncol. 2015;16(9):1090-1098. doi: 10.1016/S1470-2045(15)00040-6. Epub 2015 Aug 5.

20. Spector R, Zheng Y, Yeap BY, Wee JO, Lebenthal A, Swanson SJ, et al. The 3-Hole Minimally Invasive Esophagectomy: A Safe Procedure Following Neoadjuvant Chemotherapy and Radiation. Semin Thorac Cardiovasc Surg. 2015;27(2):205-15. doi: 10.1053/j.semtcvs.2015. 06.003. Epub 2015 Jun 20.

21. Garth AK, Newsome CM, Simmance N, Crowe TC. Nutritional status, nutrition practices and post-operative complications in patients with gastrointestinal cancer. J Hum Nutr Diet. 2010;23(4): 393-401. doi: 10.1111/.1.1365-277X.2010.01058.x. Epub 2010 Mar 23.

22. Bhatti $A B$, Rizvi FH, Waheed A, Raza SH, Syed AA, Khattak S, et al. Does prior percutaneous endoscopic gastrostomy alter postoperative outcome after esophagectomy. World J Surg. 2015; 39(2):441-5. doi: 10.1007/s00268-014-2812-8.

23. Rosati. Minimally invasive Ivor Lewis Esophagectomy (4K). Medical Expert Training Video Education may 2017.

24. Charalabopoulos A, Lorenzi B, Kordzadeh A, Tang CB, Kadirkamanathan S, Jayanthi NV. Role of 3D in minimally invasive esophagectomy. Langenbecks Arch Surg. 2017;402(3):555-561. doi: 10.1007/s00423017-1570-0. Epub 2017 Mar 1.

25. Lee JM, Chen SC, Yang SM, Tseng YF, Yang PW, Huang PM. Comparison of single- and multi-incision minimally invasive esophagectomy (MIE) for treating esophageal cancer: a propensitymatched study. Surg Endosc. 2017;31(7):2925-2931. doi: 10.1007/s00464-016-5308-9. Epub 2016 Nov 8.

26. Ionescu AN, Ghiță C, Achim IF, Constantin A, Gheorghe M, Constantinoiu S. Minimally invasive esophagectomy through modified McKeown triple approach with esophageal reconstruction and gastric pull-up for thoracic esophageal carcinoma - case report. Journal of Surgical Sciences. 2016;3(2):83-91.

27. Kenngott HG, Neuhaus J, Müller-Stich BP, Wolf I, Vetter M, Meinzer $\mathrm{HP}$, et al. Development of a navigation system for minimally 
invasive esophagectomy. Surg Endosc. 2008;22(8):1858-65. Epub 2007 Dec 20.

28. Boone J, Hobbelink MG, Schipper ME, Vleggaar FP, Borel Rinkes $\mathrm{IH}$, de Haas RJ, et al. Sentinel node biopsy during thoracolaparoscopic esophagectomy for advanced esophageal cancer. World J Surg Oncol. 2016;14:117. doi: 10.1186/s12957-016-0866-9.

29. Hikage M, Kamei T, Nakano T, Abe S, Katsura K, Taniyama Y, et al. Impact of routine recurrent laryngeal nerve monitoring in prone esophagectomy with mediastinal lymph node dissection. Surg Endosc. 2017;31(7):2986-2996. doi: 10.1007/s00464-016-5317-8. Epub 2016 Nov 8.

30. Holscher AH, Gutschow Ch. Minimal invasive surgery for esophageal cancer. The Chinese-German J of Clinical Oncology. 2004;3(4): 233-35

31. Nguyen TN, Hinojosa M, Fayad C, Gray J, Murrell Z, Stamos M. Laparoscopic and thoracoscopic Ivor Lewis esophagectomy with colonic interposition. Ann Thorac Surg. 2007;84(6):2120-4

32. Luketich JD, Alvelo-Rivera M, Buenaventura PO, Christie NA, McCaughan JS, Litle VR, et al. Minimally invasive esophagectomy: outcomes in 222 patients. Ann Surg. 2003 ;238(4):486-94; discussion 494-5.

33. Schröder W, Hölscher AH, Bludau M, Vallböhmer D, Bollschweiler E, Gutschow C. Ivor-Lewis esophagectomy with and without laparoscopic conditioning of the gastric conduit. World J Surg. 2010;34(4):738-43. doi: 10.1007/s00268-010-0403-x.

34. Zehetner J, DeMeester SR, Alicuben ET, Oh DS, Lipham JC, Hagen JA, et al. Intraoperative Assessment of Perfusion of the Gastric Graft and Correlation With Anastomotic Leaks After Esophagectomy. Ann Surg. 2015;262(1):74-8. doi: 10.1097/ SLA.0000000000000811.

35. Helminen O, Mrena J, Sihvo E. Near-infrared image-guided lymphatic mapping in minimally invasive oesophagectomy of distal oesophageal cancer. Eur J Cardiothorac Surg. 2017; 52(5):952-7.

36. Constantinoiu S, Achim Fl. Esofagectomia minim invaziva. În: Constantinoiu S, Cordos I, Ciuce C, Scripcariu V (editors). Tratat de Patologie si Chirurgie Esofagiana. Bucuresti: Editura Academiei Române; 2017. p. 649-676.

37. Nguyen NT, Dholakia C, Nguyen XM, Reavis K. Outcomes of minimally invasive esophagectomy without pyloroplasty: analysis of 109 cases. Am Surg. 2010;76(10):1135-8.

38. Stewart CL, Wilson L, Hamm A, Bartsch C, Boniface M, Gleisner A et al. Is Chemical Pyloroplasty Necessary for Minimally Invasive Esophagectomy? Ann Surg Oncol. 2017;24(5):1414-1418. doi: 10.1245/s10434-016-5742-x. Epub 2017 Jan 5.

39. Lanuti M, DeDelva P, Morse CR, Wright CD, Wain JC, Gaissert HA, et al. Management of delayed gastric emptying after esophagectomy with endoscopic balloon dilatation of the pylorus. Ann Thorac Surg. 2011;91(4):1019-24. doi: 10.1016/j.athoracsur.2010.12.055. Epub 2011 Feb 2

40. Palmes D, Weilinghoff M, Colombo-Benkmann M, Senninger N, Bruewer M. Effect of pyloric drainage procedures on gastric passage and bile reflux after esophagectomy with gastric conduit reconstruction. Langenbecks Arch Surg. 2007;392(2):135-41. Epub 2007 Jan 10.

41. Weijs TJ, van Eden HWJ, Ruurda JP, Luyer MDP, Steenhagen E, Nieuwenhuijzen GAP, et al. Routine jejunostomy tube feeding following esophagectomy. J Thorac Dis. 2017;9(Suppl 8):S851-S860. doi: 10.21037/jtd.2017.06.73.

42. Hochwald SN, Ben-David K. Minimally invasive esophagectomy with cervical esophagogastric anastomosis. J Gastrointest Surg. 2012; 16(9):1775-81. doi: 10.1007/s11605-012-1895-5. Epub 2012 May 2.

43. Mishra PK, Shah H, Gupta N, Varshney V, Patil NS, Jain A, et al. Stapled versus hand-sewn cervical esophagogastric anastomosis in patients undergoing esophagectomy: A Retrospective Cohort Study. Ann Med Surg (Lond). 2016;5:118-24. doi: 10.1016/j.amsu. 2015.12.063. eCollection 2016 Feb.

44. Ben-David K, Fullerton A, Rossidis G, Michel M, Thomas R, Sarosi G, et al. Prospective Comprehensive Swallowing Evaluation of Minimally Invasive Esophagectomies with Cervical Anastomosis: Silent Versus Vocal Aspiration. J Gastrointest Surg. 2015;19(10):1748-52. doi: 10.1007/s11605-015-2889-x. Epub 2015 Jul 23.
45. van Workum F, van der Maas J, van den Wildenberg FJ, Polat F, Kouwenhoven EA, van Det MJ, et al. Improved Functional Results After Minimally Invasive Esophagectomy: Intrathoracic Versus Cervical Anastomosis. Ann Thorac Surg. 2017;103(1):267-273. doi: 10.1016/j. athoracsur.2016.07.010. Epub 2016 Sep 24.

46. Jeon HW, Park JK, Song KY, Sung SW. High Intrathoracic Anastomosis with Thoracoscopy Is Safe and Feasible for Treatment of Esophageal Squamous Cell Carcinoma. PLoS One. 2016;11(3): e0152151. doi: 10.1371/journal.pone.0152151. eCollection 2016.

47. Maas KW, Biere SS, Scheepers JJ, Gisbertz SS, Turrado Rodriguez VT, van der Peet DL, et al. Minimally invasive intrathoracic anastomosis after Ivor Lewis esophagectomy for cancer: a review of transoral or transthoracic use of staplers. Surg Endosc. 2012;26(7):1795-802. doi: 10.1007/s00464-012-2149-z. Epub 2012 Feb 1.

48. Irino T, Tsai JA, Ericson J, Nilsson M, Lundell L, Rouvelas I. Thoracoscopic side-to-side esophagogastrostomy by use of linear stapler-a simplified technique facilitating a minimally invasive Ivor-Lewis operation. Langenbecks Arch Surg. 2016;401(3):31522. doi: 10.1007/s00423-016-1396-1. Epub 2016 Mar 9.

49. Haverkamp L, Seesing MF, Ruurda JP, Boone J, V Hillegersberg R. Worldwide trends in surgical techniques in the treatment of esophageal and gastroesophageal junction cancer. Dis Esophagus. 2017;30(1):1-7. doi: 10.1111/dote.12480.

50. Goldsmith HS, Kiely AA, Randall HT. Protection of intrathoracic esophageal anastomoses by omentum. Surgery. 1968;63(3):464-6.

51. Dai JG, Zhang ZY, Min JX, Huang XB, Wang JS. Wrapping of the omental pedicle flap around esophagogastric anastomosis after esophagectomy for esophageal cancer. Surgery. 2011;149(3):40410. doi: 10.1016/i.surg.2010.08.005. Epub 2010 Sep 20.

52. Decker G, Coosemans W, De Leyn P, Decaluwé H, Nafteux P, Van Raemdonck $D$, et al. Minimally invasive esophagectomy for cancer. Eur J Cardiothorac Surg. 2009;35(1):13-20; discussion 20-1. doi: 10.1016/j.ejcts.2008.09.024. Epub 2008 Oct 25.

53. Cuesta MA, van der Wielen N, Weijs TJ, Bleys RL, Gisbertz SS, van Duijvendijk P, et al. Surgical anatomy of the supracarinal esophagus based on a minimally invasive approach: vascular and nervous anatomy and technical steps to resection and lymphadenectomy. Surg Endosc. 2017;31(4):1863-1870. doi: 10.1007/s00464-0165186-1. Epub 2016 Aug 23.

54. Okamura A, Watanabe M, Kurogochi T, Imamura Y, Nishida K, Mine S. Mediastinal Adiposity Influences the Technical Difficulty of Thoracic Procedure in Minimally Invasive Esophagectomy. World J Surg. 2016;40(10):2398-404. doi: 10.1007/s00268-016-3562-6.

55. Ramage L, Deguara J, Davies A, Hamouda A, Tsigritis K, Forshaw M, et al. Gastric tube necrosis following minimally invasive oesophagectomy is a learning curve issue. Ann R Coll Surg Engl. 2013;95(5):32934. doi: $10.1308 / 003588413 \times 13629960045751$.

56. Bartels H, Stein HJ, Siewert JR. Early extubation vs. late extubation after esophagus resection: a randomized, prospective study. Langenbecks Arch Chir Suppl Kongressbd. 1998;115:1074-6. German

57. Inoue T, Ito S, Ando M, Nagaya M, Aso H, Mizuno Y, et al. Changes in exercise capacity, muscle strength, and health-related quality of life in esophageal cancer patients undergoing esophagectomy. Inoue et al. BMC Sports Science, Medicine and Rehabilitation (2016) 8:34

58. Cociu L. Perioada postoperatorie în chirurgia esofagiană. Tratat de Patologie și Chirurgie Esofagiană. Esofagectomia minim invazivă. București: Edit. Acad; 2017. p. 692-702.

59. Markar SR, Smith IA, Karthikesalingam A, Low DE. The clinical and economic costs of delirium after surgical resection for esophageal malignancy. Ann Surg. 2013;258(1):77-81.

60. D'Amico TA. Early feeding after esophagectomy may be too early. J Thorac Dis. 2016;8(9):E1067.

61. Dindo D, Demartines N, Clavien PA. Classification of surgical complications: a new proposal with evaluation in a cohort of 6336 patients and results of a survey. Ann Surg. 2004;240(2):205-13.

62. Zingg U, Smithers BM, Gotley DC, Smith G, Aly A, Clough A, et al. Factors associated with postoperative pulmonary morbidity after esophagectomy for cancer. Ann Surg Oncol. 2011;18(5):1460-8. 
doi: 10.1245/s10434-010-1474-5. Epub 2010 Dec 24.

63. Martin LW, Swisher SG, Hofstetter W, Correa AM, Mehran RJ, Rice DC, et al. Intrathoracic leaks following esophagectomy are no longer associated with increased mortality. Ann Surg. 2005;242(3): 392-9; discussion 399-402.

64. Bludau M, Hölscher AH, Herbold T, Leers JM, Gutschow C, Fuchs H, et al. Management of upper intestinal leaks using an endoscopic vacuum-assisted closure system (E-VAC). Surg Endosc. 2014;28(3): 896-901. doi: 10.1007/s00464-013-3244-5. Epub 2013 Oct 23.

65. Rodella L, Laterza E, De Manzoni G, Kind R, Lombardo F, Catalano F, et al. Endoscopic clipping of anastomotic leakages in esophagogastric surgery. Endoscopy. 1998;30(5):453-6.

66. Rábago LR, Ventosa N, Castro JL, Marco J, Herrera N, Gea F. Endoscopic treatment of postoperative fistulas resistant to conservative management using biological fibrin glue. Endoscopy. 2002;34(8): 632-8.

67. Schweigert M, Solymosi N, Dubecz A, Stadlhuber RJ, Muschweck $\mathrm{H}$, Ofner D, et al. Endoscopic stent insertion for anastomotic leakage following oesophagectomy. Ann R Coll Surg Engl. 2013; 95(1):43-7. doi: 10.1308/003588413X13511609956255.

68. Mungo B, Lidor AO, Stem M, Molena D. Early experience and lessons learned in a new minimally invasive esophagectomy program. Surg Endosc. 2016;30(4):1692-8. doi: 10.1007/s00464015-4343-2. Epub 2015 Jun 27.

69. Kassis ES, Kosinski AS, Ross P Jr, Koppes KE, Donahue JM, Daniel VC. Predictors of anastomotic leak after esophagectomy: an analysis of the society of thoracic surgeons general thoracic database. Ann Thorac Surg. 2013;96(6):1919-26. doi: 10.1016/j.athoracsur.2013. 07.119. Epub 2013 Sep 24

70. Davies N. Surgeon volumes in oesophagogastric and hepatopancreatobiliary resectional surgery (Br J Surg 2011; 98: 891-893). Br J Surg. 2011;98(10):1496; author reply 1496-7. doi: 10.1002/ bjs.7695.

71. Zhao L, Zhao G, Li J, Qu B, Shi S, Feng X, et al. Calcification of arteries supplying the gastric tube increases the risk of anastomotic leakage after esophagectomy with cervical anastomosis. J Thorac Dis. 2016:8(12):3551-3562. doi: 10.21037/jtd.2016.12.62.

72. Mine S, Watanabe M, Okamura A, Imamura Y, Kajiyama Y, Sano T. Superior Thoracic Aperture Size is Significantly Associated with Cervical Anastomotic Leakage After Esophagectomy. World J Surg. 2017;41(10):2598-2604. doi: 10.1007/s00268-017-4047-y.

73. Bonavina L, Bona D, Binyom PR, Peracchia A. A laparoscopicallyassisted surgical approach to esophageal carcinoma. J Surg Res. 2004;117(1):52-7.

74. Benjamin G, Ashfaq A, Chang YH, Harold K, Jaroszewski D. Diaphragmatic hernia post-minimally invasive esophagectomy: a discussion and review of literature. Hernia. 2015;19(4):635-43. doi: 10.1007/s10029-015-1363-8. Epub 2015 Mar 5.

75. Oor JE, Wiezer MJ, Hazebroek EJ. Hiatal Hernia After Open versus Minimally InvasiveEsophagectomy: A Systematic Review and Meta-analysis. Ann Surg Oncol. 2016;23(8):2690-8. doi: 10.1245/ s10434-016-5155-x. Epub 2016 Feb 29.

76. Lohani KR, Nandipati KC, Rollins SE, Fetten K, Lee TH, Pallati PK, et al. Transthoracic approach is associated with increased incidence of atrial fibrillation after esophageal resection. Surg Endosc. 2015;29(7):2039-45. doi: 10.1007/s00464-014-3908-9. Epub 2014 Nov 1.

77. Haverkamp L, Seesing MFJ, Ruurda JP, Boone J, Hillegersberg RV. Worldwide trends in surgical techniques in the treatment of esophageal and gastroesophageal junction cancer. Diseases of the Esophagus. 2017;30(1):1-7.

78. McAnena 0J, Rogers J, Williams NS. Right thoracoscopically assisted oesophagectomy for cancer. Br J Surg. 1994;81(2):236-8.

79. Luketich JD, Pennathur A, Awais O, Levy RM, Keeley S, Shende M, et al. Outcomes after minimally invasive esophagectomv review of over 1000 patients. Ann Surg. 2012;256(1):95-103. doi: 10.1097 /SLA.0b013e3182590603.

80. Luketich JD, Pennathur A, Franchetti Y, Catalano PJ, Swanson S, Sugarbaker DJ, et al. Minimally invasive esophagectomy: results of a prospective phase II multicenter trial-the eastern cooperative oncology group (E2202) study. Ann Surg. 2015;261(4):702-7. doi: 10.1097/SLA.0000000000000993.

81. Fabian T, Martin J, Katigbak M, McKelvey AA, Federico JA. Thoracoscopic esophageal mobilization during minimally invasive esophagectomy: a head-to-head comparison of prone versus decubitus positions. Surg Endosc. 2008;22(11):2485-91. doi: 10.1007/s00464-008-9799-x. Epub 2008 Mar 5.

82. Okusanya OT, Sarkaria IS, Hess NR, Nason KS, Sanchez MV, Levy RM, et al. Robotic assisted minimally invasive esophagectomy (RAMIE): the University of Pittsburgh Medical Center initial experience. Ann Cardiothorac Surg. 2017;6(2):179-185. doi:10.21037/acs.2017.03.12.

83. de la Fuente SG, Weber J, Hoffe SE, Shridhar R, Karl R, Meredith $\mathrm{KL}$. Initial experience from a large referral center with roboticvassisted Ivor Lewis esophagogastrectomy for oncologic purposes. Surg Endosc. 2013;27(9):3339-47. doi: 10.1007/s00464-013-29156. Epub 2013 Apr 3.

84. van der Sluis PC, Ruurda JP, Verhage RJ, van der Horst S, Haverkamp L, Siersemaet PD, et al. Oncologic Long-Term Results of Robot-Assisted Minimally Invasive Thoraco-Laparoscopic Esophagectomy with Two-Field Lymphadenectomy for Esophageal Cancer. Ann Surg Oncol. 2015; 22:1350-6.

85. Biere SS, van Berge Henegouwen MI, Maas KW, Bonavina L, Rosman C, Garcia JR, et al. Minimally invasive versus open oesophagectomy for patients with oesophageal cancer: a multicentre, open-label, randomised controlled trial. Lancet. 2012; 379(9829):1887-92. doi: 10.1016/S0140-6736(12)60516-9.

86. Maas KW, Cuesta MA, van Berge Henegouwen MI, Roig J, Bonavina L, Rosman C, et al. Quality of life and late complications after minimally invasive compared to open esophagectomy: results of a randomized trial. World J Surg. 2015;39(8):1986-93. doi: 10.1007/s00268-015-3100-y.

87. Straatman J, van der Wielen N, Cuesta MA, Daams F, Roig Garcia J, Bonavina $L$ et al. Minimally invasive versus open esophageal resection: three-year follow-up of the previously reported randomized controlled trial: The TIME Trial. Ann Surg.2017; 266(2):232-6.

88. Mariette C, Meunier B, Pezet D, Dalban C, Collet D, Thomas PA, et al. Hybrid minimally invasive versus open oesophagectomy for patients with oesophageal cancer: A multicenter, open-label, randomized phase III controlled trial, the MIRO trial. Journal of Clinical Oncology. 2015;33:3_suppl:5-5. DOI: 10.1200/ jco. 2015.33.3 suppl.5

89. Mariette C, Markar S, Dabakuyo-Yonli TS, Meunier B, Pezet D, Collet $\mathrm{D}$, et al. Hybrid minimally invasive vs. open esophagectomy for patients with esophageal cancer: Long-term outcomes of a multicenter, open-label, randomized phase III controlled trial, the MIR0 trial. Annals of Oncology. 2017;28(suppl_5):v605-v649. 10.1093/annonc/mdx440

90. van der Sluis PC, Ruurda JP, van der Horst S, Verhage RJ, Besselink MG, Prins MJ, et al. Robot-assisted minimally invasive thoraco-laparoscopic esophagectomy versus open transthoracic esophagectomy for resectable esophageal cancer, a randomized controlled trial (ROBOT trial). Trials. 2012;13:230. doi: 10.1186/ 1745-6215-13-230.

91. Parameswaran R, Blazeby JM, Hughes R, Mitchell K, Berrisford $R G$, Wajed $S A$. Health-related quality of life after minimally invasive oesophagectomy. Br J Surg. 2010;97(4):525-31. doi: 10.1002/ bjs.6908.

92. Mehran R, Rice D, El-Zein R, Huang JL, Vaporciyan A, Goodyear A, et al. Minimally invasive esophagectomy versus open esophagectomy, a symptom assessment study. Dis Esophagus. 2011;24(3): 147-52. doi: 10.1111/j.1442-2050.2010.01113.x. Epub 2010 Oct 11.

93. Sundaram A, Geronimo JC, Willer BL, Hoshino M, Torgersen Z, Juhasz $A$, et al. Survival and quality of life after minimally invasive esophagectomy: a single-surgeon experience. Surg Endosc. 2012; 26(1):168-76. doi: 10.1007/s00464-011-1850-7. Epub 2011 Aug 19. 